\title{
IMPACT OF LIGHTING ON CHILDREN'S LEARNING ENVIRONMENT: A LITERATURE REVIEW
}

\author{
MICHAEL LEKAN-KEHINDE \& ABIMBOLA ASOJO \\ College of Design, University of Minnesota, USA
}

\begin{abstract}
Research studies show that the physical learning environment influences the performance and wellbeing of children, supporting their development into adulthood. Lighting is a critical aspect of this physical environment. We highlight the relationship between human functionality and lighting, showing what key roles lighting plays in an optimum key environment, providing specific references to the importance of lighting for visual capabilities, body temperature, and healthy living through vitamin D production. We elucidate how lighting is a major driver for children's performance and functioning, by enabling their visual, cognitive and behavioral skills through concentration, alertness, and maintenance of children's moods. Research has also identified methodologies used to establish this relationship, which include qualitative, quantitative, mixed-method, and quasi mixed-method; and parameters such as using the progression of test scores in standardized tests, concentration over time, user behavior, and mood as the test parameters. Study results of academic performance through reading performance (accuracy, speed, and expression) under conditions similar to everyday life show that exposure to higher correlated color temperature (CCT) light leads to greater improvement in children's task-switching performance, though no impact was seen on their sustained attention. This was also established by Mott et al. as the Oral Reading Frequency (ORF) scores of students, with the lighting of $6500 \mathrm{~K}$ and $10001 \mathrm{x}$ showed increased student ORF scores compared to students receiving $3000 \mathrm{~K}$ and 500lx. Results exploring user behavior and mood test parameters indicate that blue-enriched light increases student concentration and cognitive performance (processing, speed, concentration, and memory). Here we highlight research/studies about the importance of lighting for comfort, through varying lighting scenarios; and how student behavior, learning capabilities, and cognitive skills can be improved through lighting choices.
\end{abstract}

Keywords: lighting, children, learning, environment, wellbeing, performance testing.

\section{INTRODUCTION}

Childhood provides the opportunity for children to develop lifelong skills that will support them throughout their adult lives, later on. There has been educational research focused on providing insights into the various aspects of the student learning environment, such as: learning tasks, materials, time on task, teacher's instructional behaviors, and student-teacher relationships. There remains a need for focused, systematic research into the influence of the physical aspects of students' learning environment, by measuring various factors such as air quality, noise levels/music, plants, and lighting, reported to influence childrens' performance and wellbeing [1]. Lighting was reported to be an important factor that affects student learning and growth in the classroom environment [2], [3], so this review will present the collective findings on the impact of daylight on the learning environment, plus how to enhance lighting to influence the behavior and cognitive learning capabilities of children.

\section{HUMAN FUNCTIONALITY AND LIGHTING}

The functioning of humans is enabled and directed by light; light enables visual capabilities, systemizes body temperature, reduces the chances of myopia and enables healthy living through the production of Vitamin D [1]. Human functionality is therefore heavily hinged on daylight. The Environmental Protection Agency (EPA) estimates that an average American spends $87 \%$ of time indoors, $7-8 \%$ outdoors and $5-6 \%$ in an automobile (Fig. 1) [4]. This 
data strongly suggests that the indoor and outdoor environment plays a major role in human development and functionality, and creates a healthy environment that will be key to achieving children's development and potential.

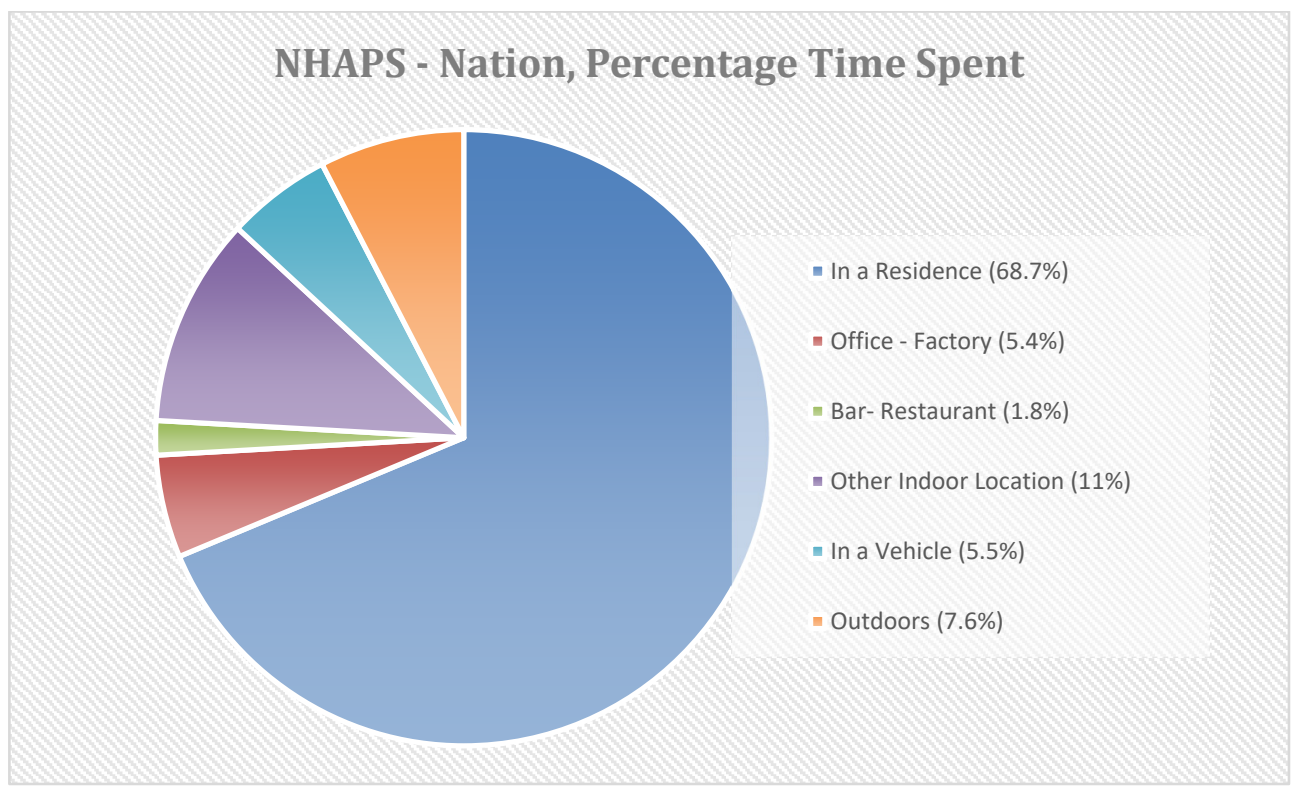

Figure 1: National US percentages for time spent in various places [4].

\subsection{Lighting and the learning environment}

In seeking to establish that human function is heavily hinged on lighting, We believe that one of the major questions for this review is to understand the key roles that light plays in an optimum learning environment. Hansen et al. [3] define the learning environment as the combination of the physical environment (the classrooms); the learning activities which take place in this environment during school hours, and the behavior of the students which would affect or might affect these activities. According to research by Boyce et al. [5], lighting (natural and artificial) has been a major driver of childrens' school performance and functioning, with windows providing natural daylight as well as a view, and artificial light further enabling children's visual, cognitive and behavioral skills inside [1]. Research by Govén et al. [6] has proven the effectiveness of blue lighting to help maintain moods during the day, leading to better concentration and alertness in adolescents who appear sleepy, due to going to sleep late. Additionally, lighting was proven effective in the development of cognitive, behavioral, and visual skills; especially from tracking materials and book visually.

\section{METHODOLOGIES AND PARAMETERS FOR STUDYING LIGHTING IN LEARNING ENVIRONMENTS}

Several methodologies and parameters have been used to determine the effectiveness of lighting in the learning environment. Methodologies vary from Qualitative; to Quantitative; to Mixed Methods (the use of both quantitative and qualitative, merged and connected); and 
Quasi Mixed (use of qualitative and quantitative research without merging them). Meanwhile, the parameters used included (Fig. 2):

(a) Using academic performance as a test parameter (this involves testing the progression of test scores and concentration over time, using standardized tests).

(b) Using behavior and mood as test parameters to study the impact of lighting on behavior, mood, and the use of lighting in the classroom to measure attentiveness, task and offtask behaviors [3].

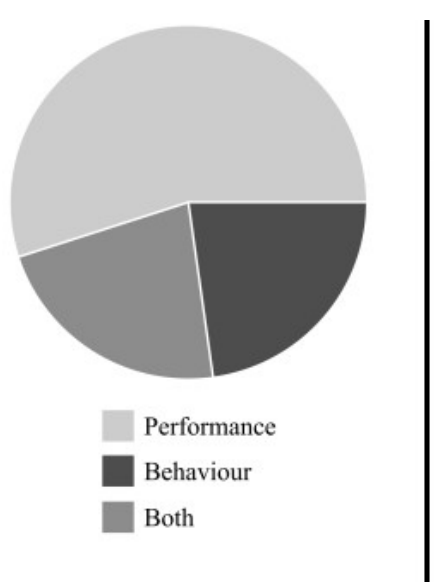

(a)

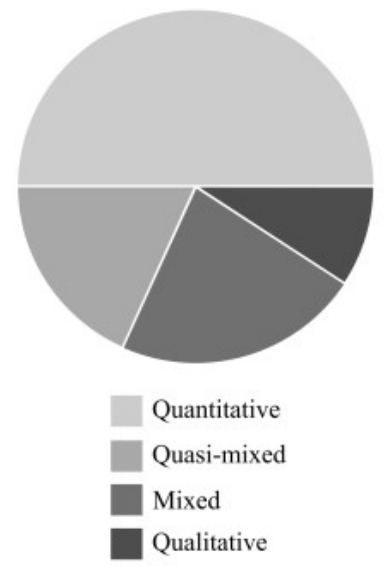

(b)

Figure 2: Methods and parameters included in selected studies. (a) Academic performance versus behavior and mood parameters induced by light conditions were tested; and (b) Approaches used in methods included Quantitative, Quasi-Mixed, Mixed and Qualitative.

In the Hansen et al. review of 21 articles in the literature between 1974 and 2016, they found $75 \%$ of them included academic parameters, with half focusing solely on performance; while about 33-34\% focused on the effects of light on student behavior, mood, and use of light. In fact, $50 \%$ of the studies, therefore, used exclusively Quantitative methods, while less than 10\% applied Qualitative; and 22\% used Mixed and 18\%, Quasi Mixed.

\subsection{Impact of lighting on the learning environment: Using academic performance as a test parameter}

One of the most common ways used to test the impact of lighting on the learning environment is the Academic Parameter, through the use of standardized tests of reading performance for accuracy, speed, and expression. Analysis by Mott et al. showed there is more improvement in reading under a "focus" setting $(6000 \mathrm{~K}, 10001 \mathrm{x})$ in comparison to the "normal" (3500K, 5001x), during their study [3]. However, further review showed a contradiction between the impacts of lighting under controlled and field experiments, indicating that lighting infield experiments, which test in conditions much closer to everyday life, could be more precise in predicting the effect of lighting on the learning potentials of students in real-life situations [3]. Hartstein et al., however, examined the light exposure influences on cognitive task 
performance in 38 preschool children aged $4.5-5.5$ by dividing them into two groups, the control $(n=18)$ and experimental group $(n=20)$, and exposing them to two different tasks aimed at measuring their sustained attention and task switching abilities, under varying lightemitting diode (LED) lighting condition of $3500 \mathrm{~K}$ or $5000 \mathrm{~K}$ [2]. The control group engaged the two-study task twice under the $3500 \mathrm{~K}$ lighting conditions, while the experimental group had the two-study task under the $3500 \mathrm{~K}$ lighting conditions as a baseline assessment, and after that, the $5000 \mathrm{~K}$ lighting conditions. They found that exposure to higher correlated color temperature (CCT) light led to greater improvement in preschool-age children's taskswitching performance, while no impact was seen in their sustained attention.

Likewise, Mott et al. [1] added further to their research in 2011 that found the usage of focus lighting (glare free, high-intensity light) to increase the ORF scores (a key index of reading comprehension) of grade 3 students. They explored the usage of focus lighting on literacy instruction on high-risk grade 3 students, using a sample size of 172 students, by establishing three lighting settings: A focus setting of $6500 \mathrm{~K}$ and $1000 \mathrm{~lx}$ for concentration, a normal setting of $3000 \mathrm{~K}$ and $5001 \mathrm{x}$ for regular classroom activities, and a calm setting of $2900 \mathrm{~K}$ and $300 \mathrm{~lx}$ for independent and collaborative learning. With the three tests conducted, they found that all students performed better on the ORF-test over time, indicating the learning effects expected of Grade 3 children; however, the differences in time within each different lighting condition suggested that the usage of a focus setting during literacy instruction has a positive influence on a gain in oral reading (Fig. 3).

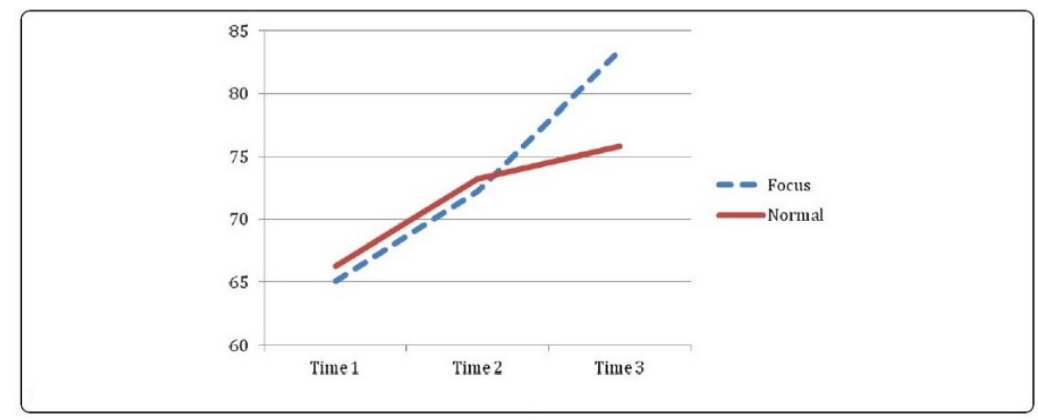

Figure 3: Means for student oral reading fluency (ORF) scores under different lighting conditions, through time [1].

Notably, over the course of a year, the focus lighting students increased their ORF scores at a greater rate, compared to the normal lighting students, as they demonstrated better words read correctly per minute (WCPM), showing that artificial lighting actually helps create an effective learning environment that is crucial to ensuring that at-risk children reach their full potential.

3.2 Impact of lighting on the learning environment: Using behavior and mood as a test parameter

Some research by Hansen et al. [3] was identified as having produced contradictory results, while others provided similar findings as related to the impact of "Normal" Color Temperature $(3000 \mathrm{k}, 4000 \mathrm{~K})$ and blue-enriched light to increase concentration and cognitive performance (processing, speed, concentration and memory) of students; however, Morrow 
and Kanakri [7] provided sound findings on the impact on learning as highly correlated to color LEDs and fluorescent lighting on students in the classroom, while recognizing LED as a more recent and preferable option for optimal energy efficiency than fluorescent (Fig. 4, additional background Fig. 5).

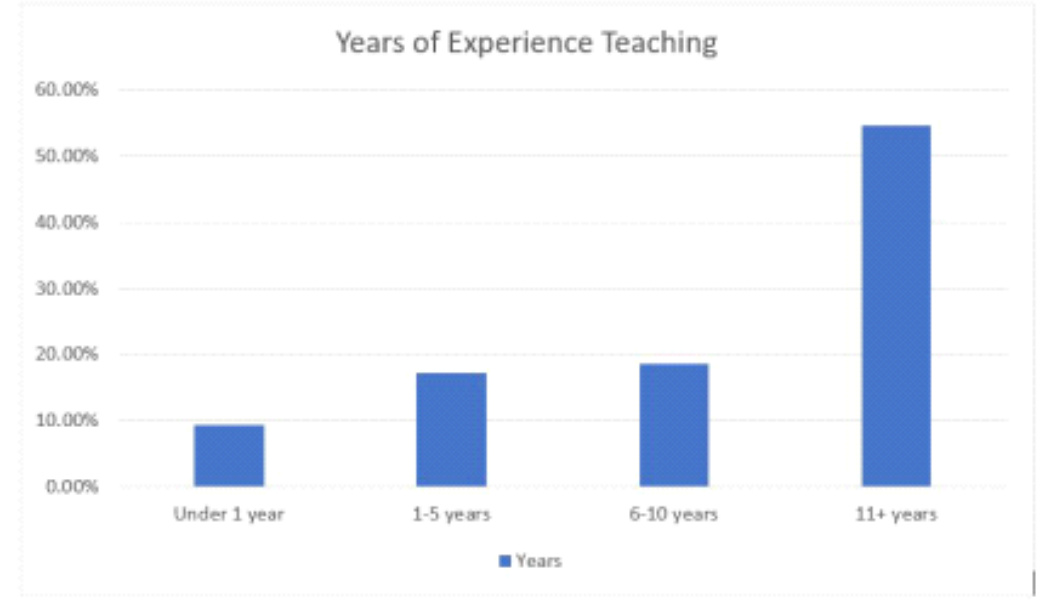

Figure 4: Year(s) of teacher experience in classroom using different light fixture lenses [7].

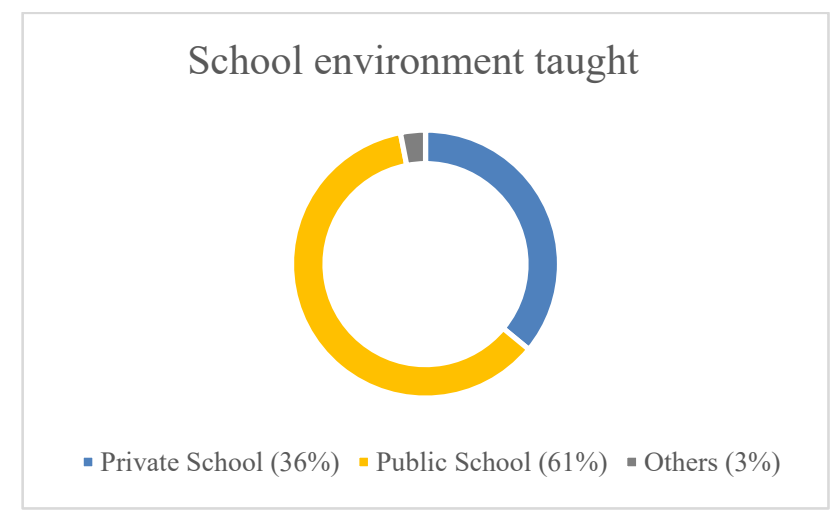

Figure 5: Percentage of teachers and type of school monitored in the Morrow and Kanakri study [7].

The findings from the data in Figures 6 and 7, obtained from 75 teachers in three Pre-K through 12 schools and other independent personal contacts, illustrated that bluer/higher kelvin $(\mathrm{K})$ temperatures emote alertness, focus, and arousal, while lower kelvin can be used for calmness; therefore, teachers preferred a $6500 \mathrm{~K}$ classroom for focusing the students' attention and on-task behaviors by $54.79 \%$, compared to $38.36 \%$ preferring a $5000 \mathrm{~K}$ lit classroom. Likewise, $81.08 \%$ of teachers indicated that adjusting lighting levels in the classroom does impact mood, attention, and engagement regarding specific activities and times of the day. 


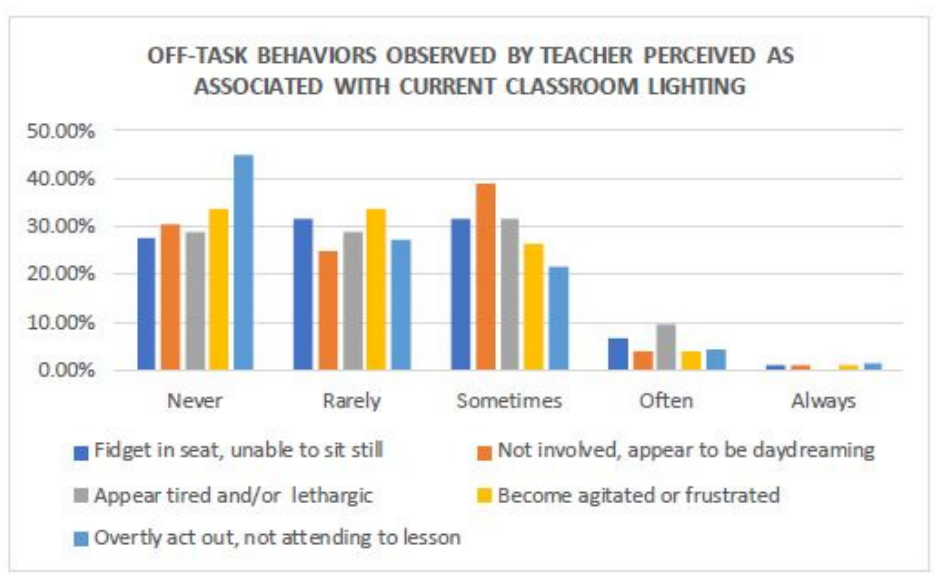

Figure 6: Teacher perception of off-task behaviors [7].

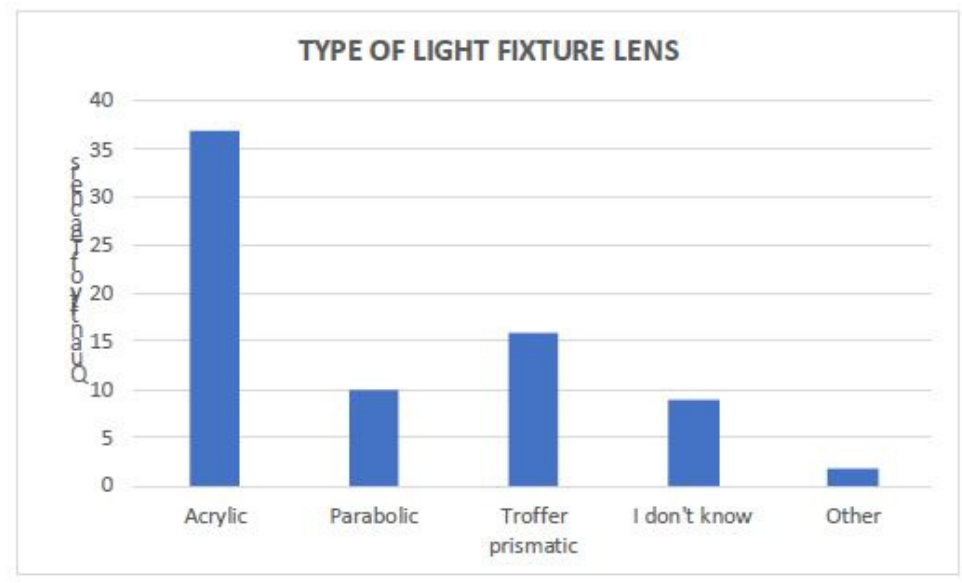

Figure 7: Percentage of teacher adjustment [7].

Taking the Morrow and Kanakri research [7] beyond the quantitative opinion of teachers Schledermann et al. [8], the former conducted a mixed field study to understand the impact of lighting on teaching and learning activities, by providing classrooms with lighting technology with four different lighting scenarios, while studying their use through a lighting control system; and combining this with observations, interviews and recording data over a three-and-a-half-month period. They focused on three classrooms for the field study: each consisted of 22 to 24 students between the ages of 11 to 12 years, with a window on one side of the room.

Four lighting scenarios included (Fig. 8): Standard, Smart Board, Fresh, and Relax. For Standard: Ceiling luminaries were at 3001x, 3500k, Board Luminaries at 5001x, 3000k, and Wall Washer was off; for Smart Board, ceiling luminaries were at 3001x, 3500k, Board Luminaries at 300lx, 3000k and Wall Washer at 3001x, 4000k; for the Fresh scenario, ceiling 

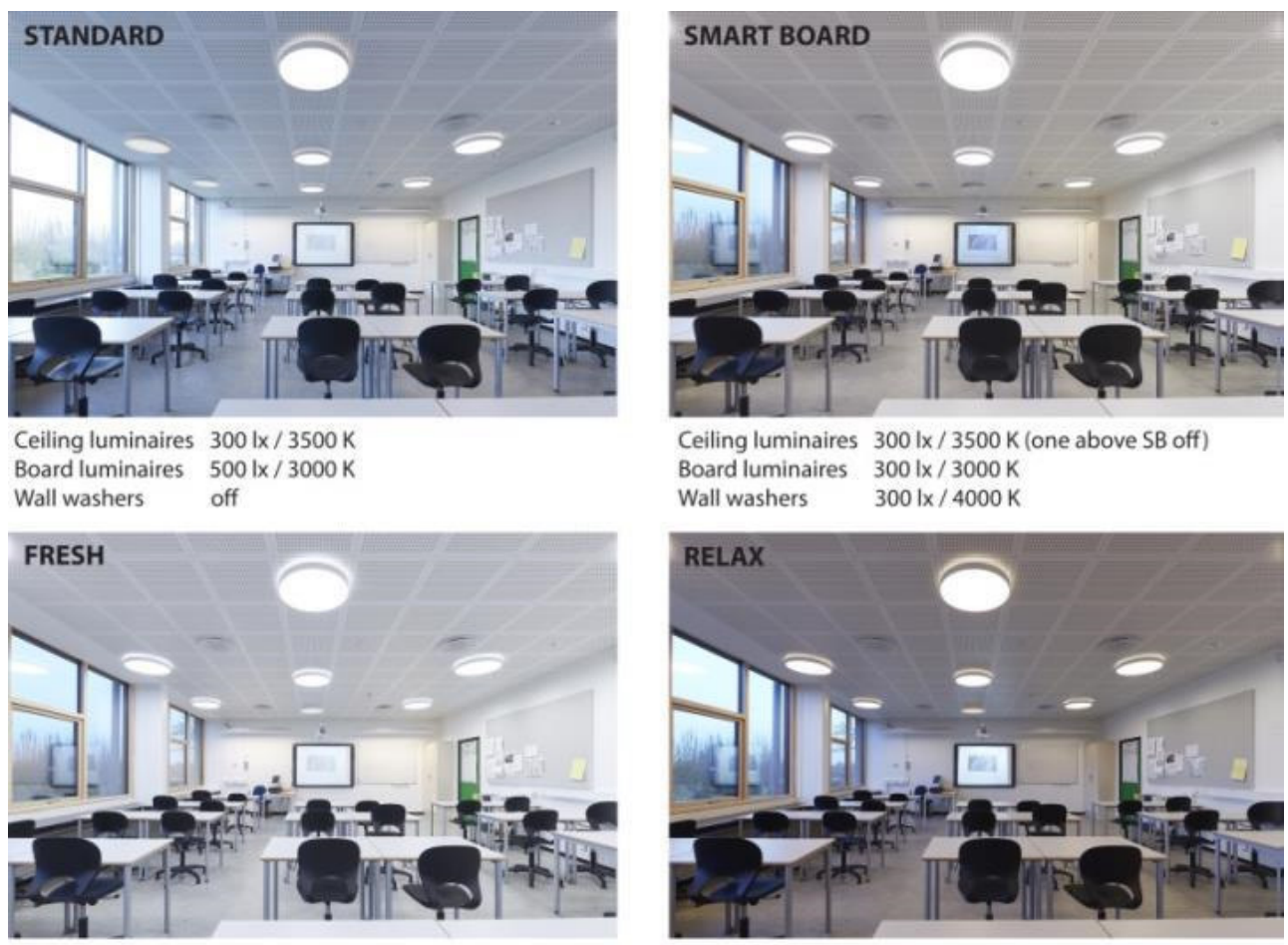

Ceiling luminaires $500 \mathrm{~lx} / 5000 \mathrm{~K}$

Board luminaires $500 \mathrm{~lx} / 3000 \mathrm{~K}$

Wall washers $420 \mathrm{~lx} / 4000 \mathrm{~K}$

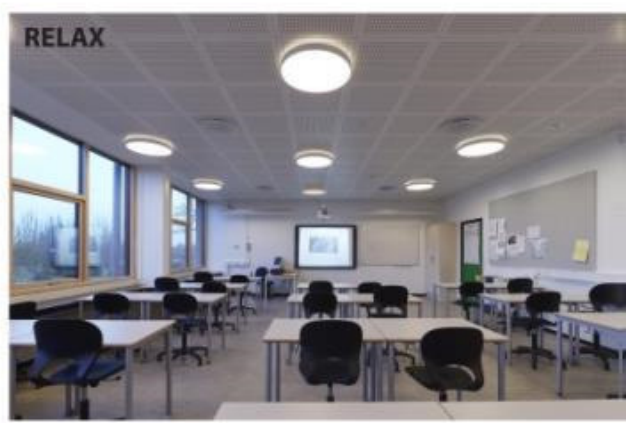

Ceiling luminaires $100 \mathrm{~lx} / 3000 \mathrm{~K}$

Board luminaires $300 \mathrm{~lx} / 3000 \mathrm{~K}$

Wall washers $\quad 75 \mathrm{Ix} / 4000 \mathrm{~K}$

Figure 8: The illumination level and correlated color temperatures of different luminary groups used in the four lighting scenarios [8].

luminaries were at $5001 \mathrm{x}, 5000 \mathrm{~K}$, board luminaries at $5001 \mathrm{x}, 3000 \mathrm{~K}$, and the wall washer at 4201x, 4000K; while for the Relax scenario, ceiling luminaries were at 1001x, 3000K, board luminaries at $3001 \mathrm{x}, 3000 \mathrm{~K}$ and the wall washer at $751 \mathrm{x}, 4000 \mathrm{~K}$.

The researchers were able to ascertain (based on the weekly averages of daily use of lighting scenarios in classrooms (Fig. 9) and the lighting scenario used by teachers during selected activities (Fig. 10)) that: (i) Changes in the lighting scenario often happened with a change in activity, during the lesson. Teachers therefore identified the use of lighting as support for different activities, with the use of an adequate lighting scenario used to structure the childrens' learning activities; (ii) Lighting could be used as a tool for communication with students, and as students became accustomed to a different light scenario, they made reminder requests for a change in lighting scenario, if the teacher forgot; (iii) Teachers used different lighting scenarios to reduce or increase the activity level of the study or change their students' behavior. Fresh was used to encourage focus; relax was used to reduce the energy level of students (Fig. 10), but also made a hypothesis that the maturity of a student in a year could have been an added reason; (iv) The varying lighting scenarios provided a varying atmosphere. An example is the use of warm-toned light, which proved effective in creating a cozy environment, making a more comfortable environment for those lagging behind. Warmer tones with decreased illuminance levels due to reduced natural light from outdoors 


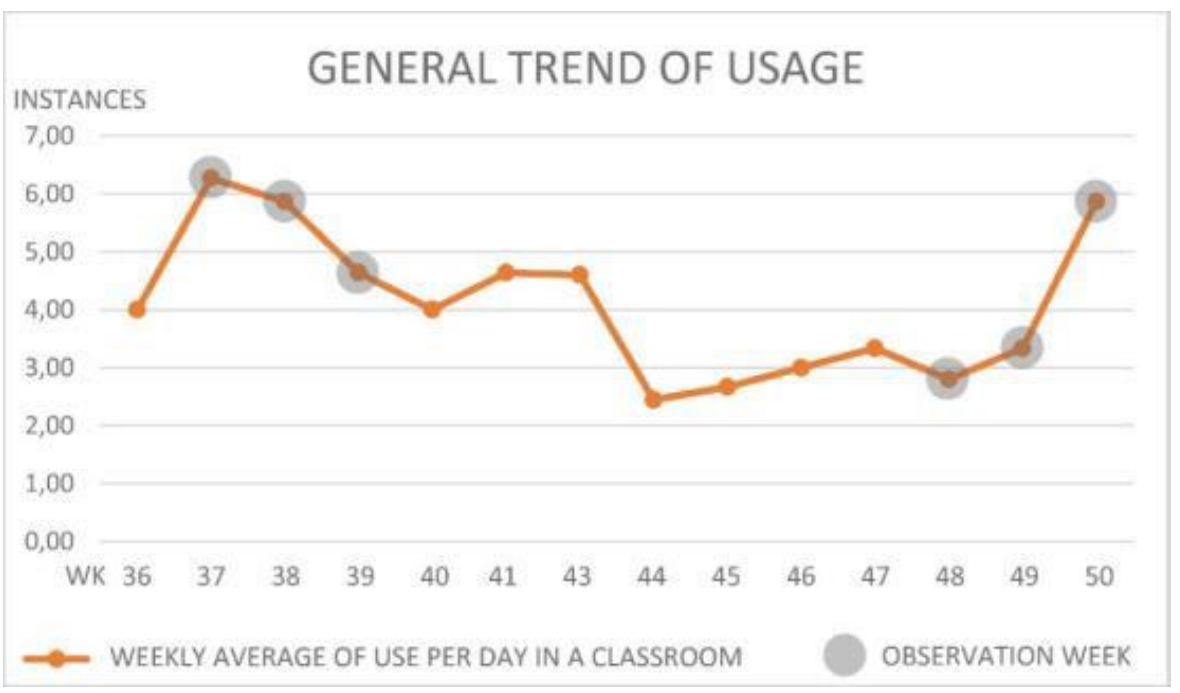

Figure 9: Weekly averages of daily use of lighting scenarios in a classroom [8].
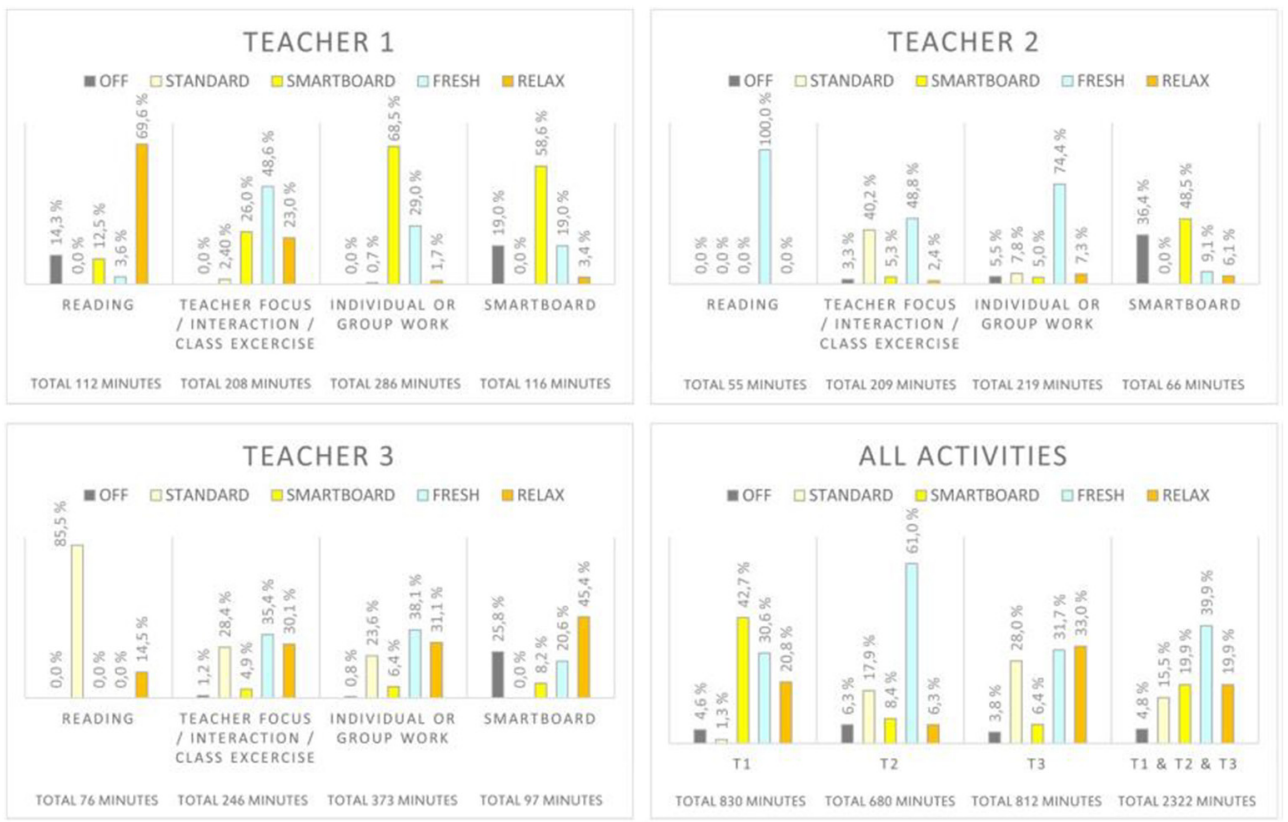

Figure 10: Relative amounts of lighting scenarios used by teachers during selected activities and all activities [8].

was used during winter; (v) The varying lighting scenarios also helped ensure suitable lighting conditions to support visual tasks and maintain visual comfort. Reduction of glare from natural sunlight by drawing the curtains, or to increase visibility of the smartboard. 
3.3 Impact of lighting on the learning environment: Using academic performance, behavior and mood as a test parameter.

The impact of lighting through both academic and the "behaviors and mood" parameters, was done by Choi and Suk [9], by investigating the effects of lighting color temperature on student performance. Three studies were carried out: A preliminary study to measure the physiological response to be able to lay a potential expectation of performance, a laboratory study, and lastly, a field study. The preliminary study measured the level of arousal of 17 healthy adults, versus adults used to provide accurate data measurement, as electrocardiogram (ECG) signals are impacted by motion artifacts. The laboratory study involved 31 visual healthy fourth-grade students whom were recruited to engage in both academic and recess activity, under three lighting conditions (3500K for easy activity, $5000 \mathrm{~K}$ for standard activity and $6500 \mathrm{~K}$ for intensive activity with an illuminance level of approximately 500 to 600 lux); but results showed no significant difference during academic activity. Therefore, no meaningful interpretations were derived relating to lighting CCTs and human behavior.

Finally, the field experiment was conducted in two fourth-grade classrooms of 27 students each, as a control and experimental group. The average age of the class was 10 years and each classroom had natural lighting coming from one side of the room. The two groups conducted arithmetic problems during different lighting exposures, as the experimental group had their fluorescent lighting replaced in the second week of the study by solid-state lighting (LED) with three lighting conditions (Easy, Standard and Intensive), as described in the laboratory study; but the control group utilized the existing fluorescent lamps throughout the experiment.

Results showed that there is a significant effect of lighting CCTs on both the academic and recess activities. Here, $6500 \mathrm{~K}$ was subjectively perceived as the most appropriate lighting for learning, while $3500 \mathrm{~K}$ received the highest average score for recess activity. Also, the results of the arithmetic activity indicated that a larger percentage of correct answers occurred with $6500 \mathrm{~K}$; and therefore, provided meaningful results to support that lighting CCT does have effects on both cognitive and behavioral performances. The Standard lighting present was advised for activities such as reading, while the Intensive lighting was pressed for problem-solving academic activities. This provided an inference that the laboratory experiment had inconsistent results due to the artificial setting, a short-time exposure to lighting, and a varying of illuminance from 445 to $5721 \mathrm{x}$.

\section{CONCLUSIONS}

The various research studies reviewed provided insight into the impacts of lighting as assessed through various methodologies; namely, the qualitative, quantitative, mixed, and quasi-mixed methods; where each provided contributions to the impact of daylight and lighting on learning environments. Major findings and understanding were established through the mixed and quasi-mixed methods, as they enabled more variables to be removed, linked and established, by reviewing the impacts of light on learning through major parameters like the moods, behavior, and academic performance of students, including high risk students, at various learning cadres. Therefore, our review further establishes the importance of lighting in learning, to ensure: (a) Comfort (mental and visual comfort) through varying lighting scenarios; (b) Provision of a suitable atmosphere that can help teachers and students switch to varying or desired tasks, either for reading, arithmetic, or recess; (c) Manage communication, as the lighting could be used to arouse concentration and discussion, 
encourage movement and group activity; (d) Enable the desired improvement in academic performance, especially for those children lagging behind and at-risk students; (e) Improve student behavior, learning capabilities, and cognitive performance, encouraging student growth.

\section{REFERENCES}

[1] Mott, M.S., Robinson, D.H., Williams-Black, T.H. \& McClelland, S.S., The supporting effects of high luminous conditions on grade 3 oral reading fluency scores. Springer Plus, 3, 2014.

[2] Hartstein, L.E., LeBourgeois, M.K. \& Berthier, N.E., Light correlated color temperature and task switching performance in preschool-age children: Preliminary insights. PLoS ONE, 13(8), 2018.

[3] Hansen, E.K., Nielsen, S.M.L., Georgieva, D. \& Schledermann, K.M., The impact of dynamic lighting in classrooms. A review on methods. Lecture Notes of the Institute for Computer Sciences, Social-Informatics and Telecommunications Engineering, LNICST. Springer Verlag, pp. 479-489, 2018.

[4] Klepeis, N.E. et al., The National Human Activity Pattern Survey (NHAPS): A resource for assessing exposure to environmental pollutants. Journal of Exposure Analysis and Environmental Epidemiology, 11(3), 2001.

[5] Boyce, P., Hunter, C. \& Howlett, O., The impact of lighting on the learning environment: A literature review, 2003. http://thedaylightsite.com/wp-content/uploads/ papers/DaylightBenefits.pdf. Accessed on: 29 Sep. 2021.

[6] Govén, T., Laike, T., Raynham, P. \& Sansal, E., Influence of ambient light on the performance, mood, endocrine systems and other factors of school children. Sun City, 2011.

[7] Morrow, L.B. \& Kanakri, M.S., The impact of fluorescent and LED lighting on students' attitudes and behavior in the classroom. Advances in Pediatric Research, 2018.

[8] Schledermann, K., Pihlajaniemi, H., Sen, S. \& Hansen, E.K., Dynamic lighting in classrooms: A new interactive tool for teaching. Lecture Notes of the Institute for Computer Sciences, Social-Informatics and Telecommunications Engineering, LNICST. Springer Verlag, pp. 374-384, 2019. www.epa.gov/epaoswer/hazwastes/test/main.htm. Accessed on: 23 Jun. 2015.

[9] Choi, K. \& Suk, H.-J., Dynamic lighting system for the learning environment: Performance of elementary students. Optics Express., 24(10), 2016. 